\title{
Tutor at the preparatory faculty: a teacher's point of view
}

\author{
Marina Anatolievna Droga*, Dina Ivanovna Romero Intriago, Irina Mikhailovna Subbotina \\ and Yuliya Aleksandrovna Klimova
}

Belgorod National Research University, Department of Russian Language, Professional Speech and Intercultural Communication, Belgorod, Russia

\begin{abstract}
The article analyzes the experience of tutoring teachers teaching foreign students in the distance learning mode. It is also about the interaction of a teacher and a student throughout the whole academic year, as well as the importance of all elements of systematic work in teaching Russian as a foreign language from scratch. A team of tutors was organized at the faculty, whose mission was to contact their wards within the framework of distance learning: from their connection to the educational platform of the university to organizing their admission to Russian universities. Purpose of the study: consider the role of a tutoring teacher in the system of teaching Russian as a foreign language in a distance mode. The main methods of work are the methods of observation and description of the features of the pedagogical process. The forecasting method is also used to model the future educational mode of foreign students. The survey method is applied, which allows to get "feedback" from the respondents. The quantitative technique allowed us to analyze the number of responses as a percentage. The changes taking place in the world have given a powerful impetus to the improvement of digital educational resources. Teachers were able to mobilize and conduct their own experiment, while adhering to the new standards of distance learning. An attempt is made in the work to comprehensively analyze the introduced system of tutoring and summarize its first results.
\end{abstract}

Keywords: curator, tutoring, Russian as a foreign language, foreign students, distance learning

\section{Introduction}

Education involves continuous systematic activity aimed both at the formation and development of individual properties and qualities of a student, and at creating the most favorable conditions for personal development in general [1]. A significant role in the solution of these pedagogical problems in the system of higher professional education has been and continues to be traditionally assigned to the curators of academic groups. A kind of institution of class teachers, called educators (in Belgium, for example) or tutors (in

\footnotetext{
*Corresponding author: m.droga84@.gmail.com
} 
England), exists in most countries of the world and is recognized as absolutely necessary [2].

The idea to conduct the study was born in connection with an urgent need: to comprehend the modern conditions of the educational environment. Higher education workers faced a difficult barrier that the improvement of skills and competencies within the framework of advanced training courses, and, of course, timely and prompt education in the framework of the rapid technological progress helped to overcome.

\section{Methods}

The main methods used in the study were the scientific literature analysis method, the comparative analysis method, and the secondary data analysis method. The article also uses the results of an online survey of teachers of the preparatory faculty of the NRU BelSU on the development of the online environment in the context of coronavirus infection, conducted from March 15 to March 20, 2021. A survey was also conducted among foreign students from Latin America who studied at the preparatory faculty in the 2020-2021 academic year.

\section{$3 \quad$ Results}

Puzzled by the solution of many issues, we conducted a survey among the teachers of the Department of Russian Language, Professional Speech and Intercultural Communication, who teach foreign students at the preparatory faculty of the NRU BelSU and also at the Institute of Intercultural Communication and International Relations, in order to find out the features of the current situation of the problem under study.

The respondents did not provide personal information. The number of participants who took part in the experiment was 30 . The teacher had to choose the appropriate answer options.

The experiment was attended by teachers belonging to different age categories (see Fig.1).

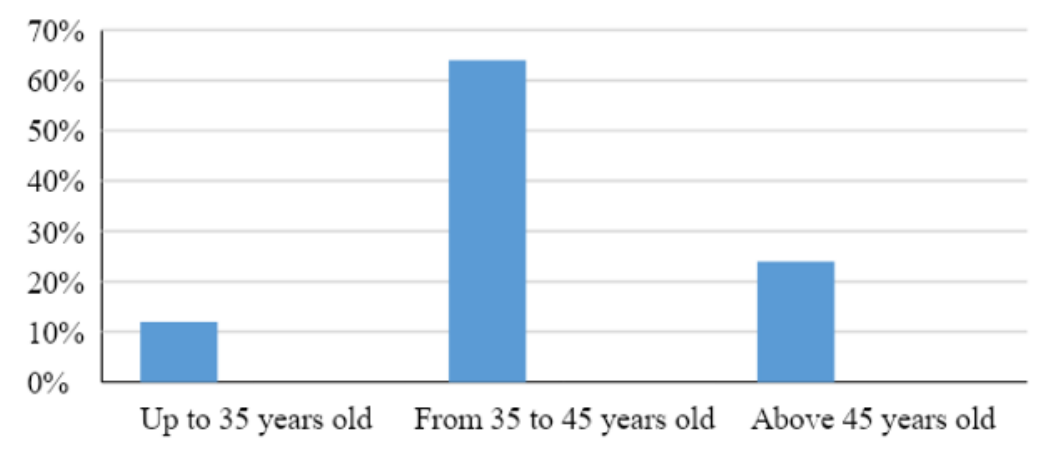

Fig. 1. Age of respondents.

As we can see, the subjects in the amount of $64 \%$ of the total number are the largest group. This fact is subject to official statistics: the contingent of teachers working in universities, for the most part, consists of teachers who received higher education in the period from 2001 to 2007 . Employees who have recently graduated from university have 
found employment outside of their profession or have chosen a job that does not require annual competitive requirements. More than half of the subjects are teachers of the so-called "middle age", who managed to get the required amount of teaching practice, as well as to gain experience, providing them with a sufficient level of competence to conduct teaching. There are $12 \%$ of male teachers of the total who took part in the experiment. Among the respondents are male linguists.

The next question on the questionnaire was a question about the discipline taught to foreign students. The survey results can be seen in the diagram (see Fig. 2).

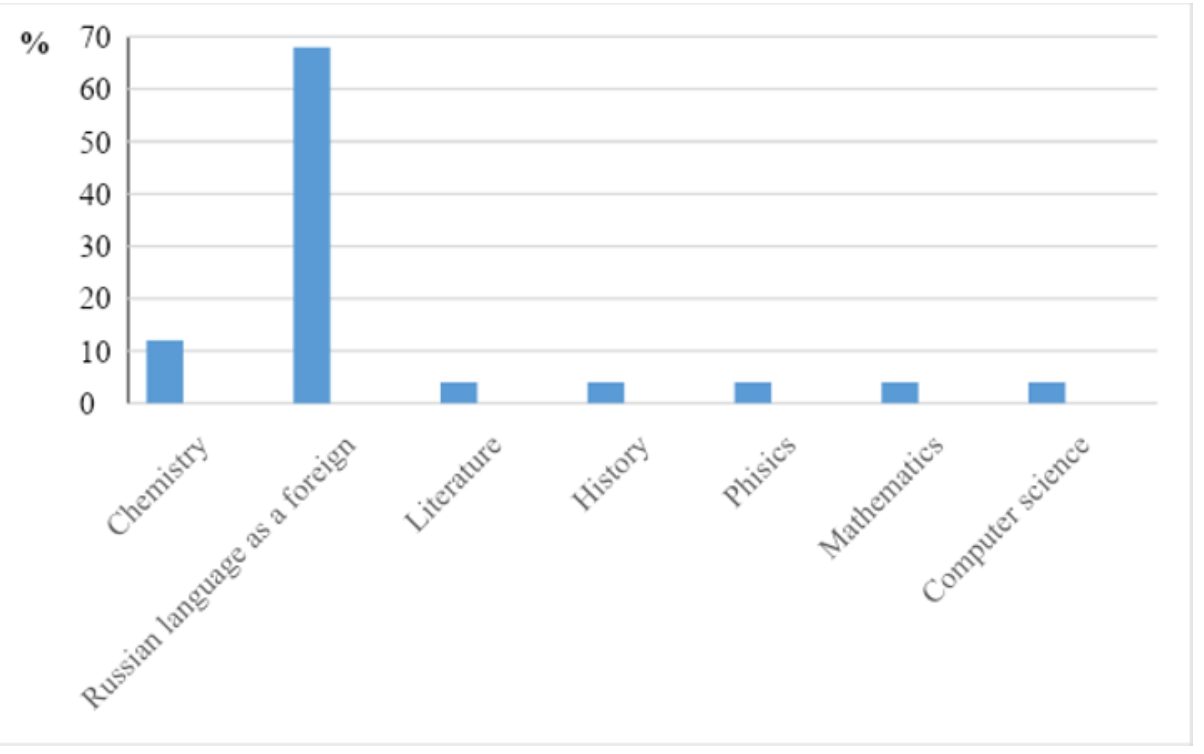

Fig. 2. Discipline taught.

There is the majority of teachers teaching the disciplines of the humanitarian cycle, which is $68 \%$. This educational sector includes Russian language, history, and literature. The number of natural science teachers amounts to $12 \%$ (physics, mathematics, computer science). Chemistry teachers are also $12 \%$ of the total.

It is affected by the refusal or unwillingness of teachers over 45 to fulfill the duties of a tutor. There are many reasons for this: the involvement of teachers in scientific events, the lack of a stable Internet connection, the inability to be mobile 24 hours a day, health problems, lack of skills in working with social networks, applications and messengers (WatsApp, WeChat) and a number of other factors.

From the experience of teachers who are at the same time tutors of foreign students, the following conclusions can be drawn. Undoubtedly, all the efforts of a teacher are aimed at improving the comfort of a student's education conditions. Teachers who performed tutoring duties in the groups where they taught their students have high rates of productivity in their work. After all, a foreigner who is not in Russia, does not see the organization of teaching from the inside, asked, is asking and will ask questions to the one with whom they are in contact most of the time. It turns out that a teacher who does not teach classes in those groups where they are a tutor complicates the course of activities both for themselves and for students. This fact is the starting point for adjusting the further course of the tutor corps.

The next thing is the issue of the need to entrust the teacher with the role of a tutor, which is very acute and important. Practice shows that this is a forced necessity, the 
specifics of working with foreign students. There is a rule that works here: "Who, if not we, know our students better than anyone else?" Relationships in a distance mode with such tutoring teachers are much better, stronger, and also more effective, since the process of mastering Russian language is faster than for those students who do not have the opportunity to communicate with Russian people during non-academic times. This issue is also debatable, since the time difference ( -8 hours with students from Latin America; +5 hours with students from China) puts a teacher in harsh working conditions.

At the end of a difficult academic year, we conducted a survey of foreign students in the google form from Latin America (70\% of the total number of students, which is 400) in Spanish. It took place from June 15 to June 30, 2021. We have processed 70 questionnaires. The students had to answer several questions about the conditions of distance learning of Russian language. One of them was the question of the form of learning a foreign language (individually, in a group, in a distance mode) (Fig. 3), as well as the need for a teacher/mentor in organizing the educational process.

The results of the student survey are as follows.

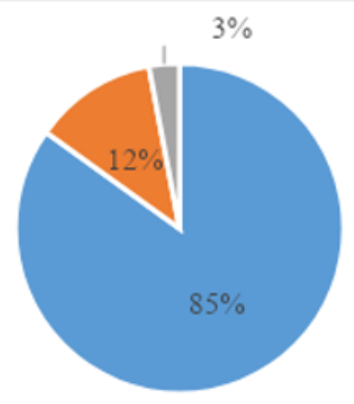

in a group of 7 to 10

students

individuall

in remote mode

Fig. 3. Preferred form of study.

Only $3 \%$ of the subjects preferred the distance mode. This is due to the fact that listeners have the opportunity to get an education "without leaving home". Financial costs are minimal, since a foreigner does not need to purchase expensive tickets or pay for accommodation in Russia. In addition, they have the opportunity to work while studying at the university according to a convenient schedule. Also, people with disabilities got a chance to learn the language remotely.

Practice proves that under the conditions of distance learning, the volume and complexity of the load of independent work of students increases: "it is in these conditions, more than ever before, in the conditions of prolonged dialogue and limited means of its organization, students need specific recommendations from a teacher on the organization of independent work, in the indirect management by the teacher, who in the conditions of distance learning is forced to change their role of mentor to the role of preceptor and tutor" [3].

Having analyzed the features of organizing distance learning during the coronavirus pandemic, it can be noted that:

- this form of education, while not new, was applied infrequently and locally; during the pandemic, it became widespread without an adaptation period. Interactive student-teacher interaction was more often carried out via Skype, ZOOM applications, using the corporate Pegasus program, via e-mail, social media chats and messengers; 
- quarantine measures highlighted a number of relevant issues, such as a decrease in the level of motivation for learning, an increase in the number of tasks for independent work, almost turning it into extramural learning [4], the impossibility at this stage of creating individual options for distance learning, overload of educational sites, heterogeneous technical equipment of teachers and students, which generally affected the quality of education, led to its noticeable deterioration [5];

- there was an awareness of the need to introduce new, effective and affordable pedagogical methods that would preserve and improve the quality of education in the context of mass distance learning [6], the so-called post-pandemic pedagogy [7], which should probably also rely on pedagogical experience of foreign colleagues who have used digital tools and have achieved some success in achieving engagement, active learning and team learning of students [8]. Many of them note that the situation in the field of distance learning is not just a technical problem but a pedagogical challenge [9], write about the need to immediately change the pedagogical approach and adapt to new contextual conditions [10].

\section{Discussion}

E-learning, introduced in the 1990s as a result of using the Internet and the Internet based tools, is widely used in teaching foreign languages. Various training programs have been implemented for distance learning. Innovative technologies are widely used in the educational process, integrating theory and practice. Implementation of new technologies has changed the teaching process and has involved new roles for the teacher. The teacher-centred educational process has been replaced by student-centred learning. This means that a student's needs and interests are taken into consideration, while the teacher becomes a tutor or a guide who is ready to help. As a result, language acquisition becomes much more effective [11].

The specificity of working with foreign students is that they are not grouped according to gender, nationality or age. At the Belgorod State National Research University, the system of forming communities has been developed by the authorities and it has proven itself well. The community leaders, consisting of professional teachers who have been working with foreign students for several years, carry out curatorial work during the academic year in accordance with the University Charter. As part of social work and attracting foreign students to socially useful work, the curators traditionally carried out the following work:

- on solving social and domestic issues (living in a hostel, etc.);

- within the framework of educational work (monitoring progress, attendance, providing the necessary literature);

- in the field of legal education (prevention of offenses and extremist manifestations among foreign students; meetings with employees of migration services, etc.);

- on the development of intercultural interaction and the creative potential of students (together with the Center for Intercultural Communication, the Center for Patriotic Education and other institutions of the city and region);

- on the organization of sports and recreation (Health Days, participation of students in the cup of community, etc.).

In connection with the pandemic that changed the world, this system has undergone many changes. Targeted work with every foreigner came to the fore. In the conditions of distance learning, the formation of a team of tutors working remotely at the preparatory faculty turned out to be relevant. It included teachers (full-time employees) and new 
personnel of educational institutions during the pandemic. One of the main tasks of teachers was "to reduce costs and search for new resources and strategies" [12].

A modern Russian preparatory faculty is a multicultural space where foreign students from many countries interact. It is here that a dialogue of cultures of representatives of different peoples occurs. And here intercultural communication of students with each other and with Russian teachers is realized [13].

Difficulties relate to the issues of organizing interaction with other subjects (communication style, behavior during online classes, adherence to the norms of netiquette), individual educational routes (choice of courses, modules, monitoring forms, etc.), self-organization (optimal mode, time management skills and others), as well as difficulties associated with the perception, processing and assimilation of information presented in various types and forms, in the conditions of the information and educational environment of an educational institution [14].

The students are more matured than previous time. Now education depends on Thinking Skills, Interpersonal Skills, Information Media, Technological skills as well as Life Skills and tutor's activities should be connected inextricably with them $[15,16]$.

\section{Conclusion}

The tutoring system is not an innovation in the educational process at the preparatory faculty. This is a well-forgotten "old" functional tool that allows you to interact with students located anywhere in the world [17]. The survey of teachers and students showed that with all the existing problems, the 2020-2021 academic year can be considered complete, and the process of mastering Russian language can be described as satisfactory. However, within the groups in which tutoring teachers worked, a greater number of applications for admission to universities with the aim of further education in Russia were recorded. Foreigners are not afraid of the prospect of learning in a distance mode and beyond. Teachers, in turn, intend to adjust the educational course in virtual environments. In addition, they set the goal of mastering "the skills of managing all applied programs and constantly monitoring trends in digital learning in other countries" [18].

\section{References}

1. A.D. Zonova, G.V. Simonova, N.K. Shmakova, Act Prob Edu, 1, 258-262 (2014)

2. N.F. Bolshakova, I.P. Mironov, BelIRO Bul, 4(6), 17-19 (2013)

3. O.V. Okhlupina, Higher Edu Today, 7, 24-28 (2020). https://doi.org/10.25586/RNU.HET.20.07.P.24

4. L.B. Schneider, Higher Edu Today, 7, 18-23 (2020). https://doi.org/10.25586/RNU.HET.20.07.P.18

5. L.V. Mrochko, T.M. Roshchina, N.S. Roshchin, Econ Socio-Human Res, 2(26), 142-146 (2020). https://doi.org/10.24151/2409-1073-2020-2-142-146

6. N.R. Bukeykhanov, S.I. Gvozdkova, E.V. Butrimova, Rus Reg: Look Future, 7(2), 62-75 (2020)

7. Murphy M. Contemp Sec Pol, 41(3), 492-505 (2020). https://doi.org/10.1080/13523260.2020.1761749

8. H.R. Tan, et al., J Chem Edu, 97(9), 2512-2518 (2020). https://doi.org/10.1021/acs.jchemed.0c00541 
9. A. Wahab, Higher Edu, 10(3), 16-25 (2020). https://doi.org/10.5539/hes.v10n3p16

10. E. Liguori, C. Winkler, Entrepr Edu Pedag, 3(4), 346-351 (2020). https://doi.org/10.1177/2515127420916738

11. L.S. Chikileva, Integ Edu, 23(3(96)), 475-489 (2019). https://doi.org/10.15507/1991-9468.096.023.201903

12. S.A. Asanov, G.V. Akimenko, Diary Sci, 7(43), 18 (2020). https://doi.org/10.4018/IJDET.20210101.oa3

13. N. Filimonova, et al., Adv Soc Sci. Edu Human Res, 198, 260-265 (2018). https://doi.org/10.2991/ictppfms-18.2018.46

14. N.V. Iltakova, A.O. Pustovarova, E.G. Kopalkina, Soc Compet, 5(4(18), 483-493 (2020)

15. B. Djumanova, K. Makhmudov, Sci Edu, 1(1), 554-557 (2020)

16. 7 roles of a Teacher in the 21 st Century (2018). Accessed on: October 19, 2021. [Online]. Available: https://etoninstitute.com/blog/the-7-roles-of-a-teacher-in-the-21st-century

17. M.A. Droga, Bul Belgorod Inst Devel Edu, 4(6), 130-134 (2017)

18. O.M. Chorosova, S.O. Petrova, Bul Northeast Fed Univ. Ser: Pedag. Psych. Philos, 4(20), 86-90 (2020) 